\title{
Inversion for Constitutive Model Parameters of Bird in Case of Bird Striking
}

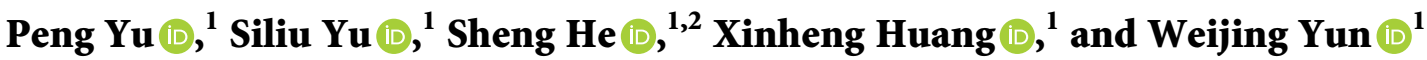 \\ ${ }^{1}$ College of Civil Engineering and Architecture, \\ Key Laboratory of Disaster Prevention and Structural Safety of Ministry of Education, \\ Guangxi Key Laboratory of Disaster Prevention and Structural Safety, Guangxi University, Nanning, China \\ ${ }^{2}$ Guangxi Bossco Environmental Protection Technology Co., Ltd, Nanning 530007, China \\ Correspondence should be addressed to Sheng He; hesheng@gxu.edu.cn
}

Received 19 November 2021; Revised 31 December 2021; Accepted 7 January 2022; Published 9 February 2022

Academic Editor: Jingxuan Wang

Copyright $\odot 2022$ Peng Yu et al. This is an open access article distributed under the Creative Commons Attribution License, which permits unrestricted use, distribution, and reproduction in any medium, provided the original work is properly cited.

\begin{abstract}
The strike between flying birds and airplanes results in the unacceptable losses of aircraft structures. The normal approach to evaluate the bird impact resistance is the combined full-scale experimental-numerical study. However, the simulation results from the current available bird constitutive models are usually not in good agreement with the experimental data. Establishing a reasonable bird constitutive model is difficult and significant to the simulation of the bird striking process. In this paper, based on the displacement measurements of an aluminum plate subjected to soft body impact, an inversion of the bird constitutive model is conducted by using backpropagation (BP) neural network. A comparative evaluation of this inversion model and other constitutive models is carried out, indicating that the proposed inversion model is more reasonable.
\end{abstract}

\section{Introduction}

The strike between flying birds and airplanes frequently results in catastrophic damage to the aircraft. According to the International Bird Strike Committee, 55 fatal accidents, in which 108 aircraft were damaged and 277 people died, were reported between 1912 and 2009 [1]. The serious events of birds striking can lead to an unacceptable loss of aircraft and the death of crewmembers. In early studies, the common method to determine the capability against bird strikes is to carry out a full-scale bird-strike experiment [2]. However, various uncertainties may lead to diversities of experiments, and the experiments cost much. The development of advanced numerical techniques and computing technologies makes it possible to perform the coupling analysis and simulate the whole process of bird strike problems. However, the numerical results of current models are not in good agreement with the experimental data. Establishing a reasonable bird constitutive model is significant to the finite element analysis of bird strikes on aircraft structures.

The anatomic structure of birds includes several internal cavities like pneumatic bones, lungs, and peculiar air sacs, which is a complex nonlinear system. Moreover, the identification of a bird constitutive model and the corresponding material parameters is difficult. Several authors used an elastic-plastic bird constitutive model with a defined failure strain [3-5], while others highlighted the limitations of this simplified material law [6]. It was observed that no fluid-like flow response can be achieved with such an elastic-plastic model, only if the shear modulus $G$ is set very low [7]. In Ref. [8] a rubber-like hyper-elastic Mooney-Rivlin model was adopted to simulate the bird's behavior. A more common method is an equation of state (EoS) for the bird constitutive model, by defining the pressure-volume relationship with parameters of water at room temperature. A polynomial form of the EoS and a simpler Murnaghan EoS were used in most studies [2, 9-14]. A further approach of the Grüneisen EoS was adopted in Refs. [15, 16]. However, in Ref. [17] it was reported that the Grüneisen EoS is only valid for solid materials that remained in the solid-state during the impact process and should therefore be carefully used for bird strike simulations and the usage of Grüneisen EoS dependent on the finite element code, since there are only a few of the abovementioned algorithms available in most commercial 
software codes. The material constants of all EoS have to be defined, which cannot be measured directly.

A regular technique is the parameter calibrations, for example, the elastic, elastic-plastic, or nonrevolving flow model is assumed to be the bird constitute model, and then the plate response during the bird-plate impact experiment is used to confirm the parameters of the constitutive model. This methodology was performed in studies such as $[16,18]$ using optimization software to determine the parameters in conjunction with bird strike experiments on instrumented plates. Nishikawa et al. [19] impacted gelatin birds on rigid targets and confirmed that the deformation of the bird model did behave like fluid and numerical simulation results correlated well with experiment data.

In recent years, the artificial neural network (ANN) has provided a fundamentally practical and powerful approach to material modeling. The basic advantage of ANN is that it does not explicitly need physical knowledge of the deformation mechanism and mathematical model. Darryl et al. [20] used a contact algorithm based on the Lagrange multiplier method to predict appropriate impact force, this method solved the severe contact-induced deformation due to a large contact force and highly deformable projectile. Previous studies usually adopted the Lagrangian formulation to model bird strikes. However, due to element instability, refining mesh elements and narrowing the timestep method had to be used to alleviate the problem, to solve this problem, nowadays more researchers use arbitrary Lagrange-Euler (ALE) [19, 21-23] and smoothed particle hydrodynamics (SPH) [19, 24-27] method in bird strike problems [25]. However, there are few reports about the application of ANN to model the bird constitutive model by using SPH Formulation during the impact process. In this paper, based on the displacement measurement results of bird impact on the aluminum plate, an ANN model with an error backpropagation learning algorithm has been applied to an inversion on bird constitutive model parameters and the parameters are obtained by inversion. The validity and reliability of the inversion model are discussed. Furthermore, a comparative evaluation of three other constitutive equations and the trained network model is carried out.

\section{Introduction of BP Neural Network}

The artificial neural network is an intelligent informationtreatment system with the characteristics of adaptive learning and treating complex relationships [28]. An artificial neural network (ANN) consists of a large number of highly connected artificial units (neurons or nodes). Each neural network comprises an input layer, an output layer, and one or more hidden layers, which are connected by the processing units, as can be seen in Figure 1. The input layer is used to receive data, while the output layer sends the output values to users. The role of the hidden layer is to provide the necessary complexity (which denotes to abstract the characteristics of the input data to another dimension space to show its more abstract features) for nonlinear problems. In the present model, sigmoid functions are employed due to the processing units for computational convenience.

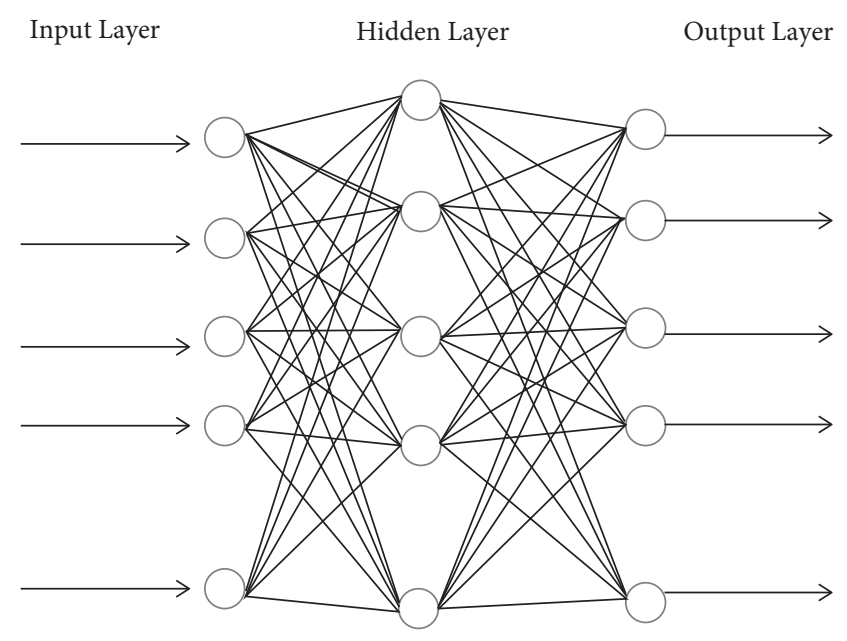

FIGURE 1: The architecture of the BP ANN model.

$$
f(x)=\frac{1}{(1+\exp (-x))}
$$

Among various types of ANN models, an iterative gradient algorithm called backpropagation (BP) algorithm is popular in the field in engineering applications and it is used for the present work. The training of a network by backpropagation involves three stages: the feedforward of the input training pattern, the training and backpropagation with the associated error, and the adjustment of the weights. When the artificial neural network is established for the soft body constitutive model, a feedforward backpropagation algorithm is selected to train the network.

\section{An Example}

3.1. Flow of Soft Body Parameter Optimization. First of all, determine the soft body parameters to be optimized, and then according to the experience to determine the range of parameters, the values determined according to the experimental data of the soft body impact aluminum sample points. And then the sample parameters in LS-DYNA in the calculation, can get aluminum midpoint displacement curve of time, choose corresponding time point in the experimental data of the displacement, training sample is completed. After the improved BP neural network training, the required soft body model parameters are output and the stable network unit connection weights are obtained. Then network training is carried out to obtain the soft body model parameters. Lastly, the obtained parameters are put into LS-DYNA for calculation, and the calculation results are compared with the experimental results. The flow chart of soft body parameter optimization as shown in Figure 2.

3.2. Construction of Bird Body Constitutive Model. Newtonian fluid is selected to describe the constitutive model of the bird body, since the real bird body is a structure with flesh and blood [29]. Newtonian fluid is a viscous fluid 


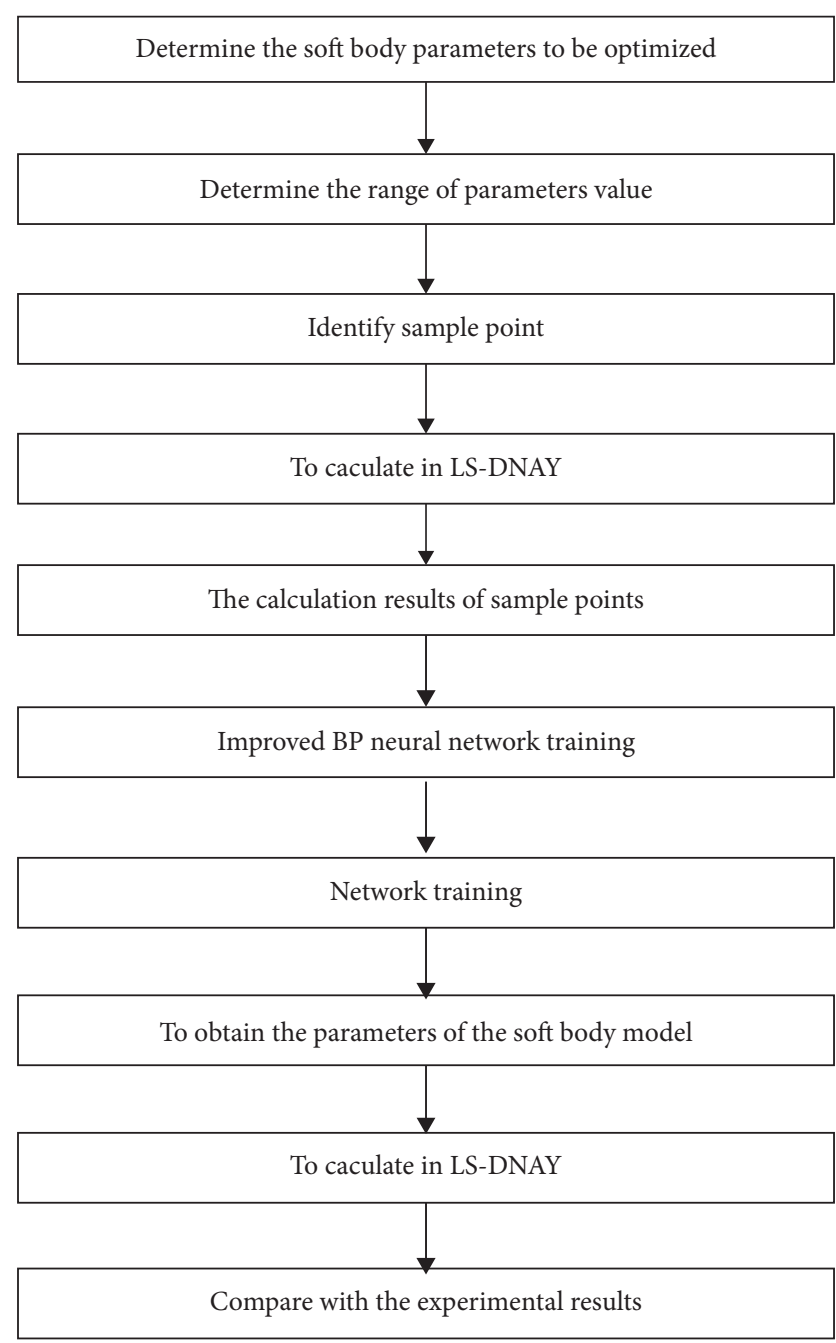

FIGURE 2: Flow chart of soft body parameter optimization.

with a linear proportional relationship between shear stress and deformation gradient, and its stress-strain relationship is determined by the following equation:

$$
\sigma_{i j}=-p \delta_{i j}+D_{i j k l} V_{i j}
$$

where $\sigma_{i j}$ is the stress tensor, $V_{i j}$ is the deformation rate tensor, $D_{i j k l}$ is the viscosity coefficient tensor of fluid, and $P$ is the static pressure. The term $p \delta_{i j}$ represents the state of stress in the fluid at rest (when $V_{i j}=0$ ). Assume that static pressure $P$ depends on the density and temperature of the fluid according to some equation of state. For Newtonian fluids, we assume that the elements of the tensor $D_{i j k l}$ can be temperature-dependent and the stress or deformation rate is independent. Tensor $D_{i j k l}$ is of order 4 with $3^{4}=81$ elements.

If the fluid is isotropic, that is, the tensor $D_{i j k l}$ has the same component matrix in any Cartesian rectangular system, then $D_{i j k l}$ can be expressed by two independent constants $\lambda$ and $\mu$ as the following equation:

$$
D_{i j k l}=\lambda \delta_{i j} \delta_{k l}+\mu\left(\delta_{i k} \delta_{j l}+\delta_{i l} \delta_{j k}\right) .
$$

Then,

$$
\sigma_{i j}=-p \delta_{i j}+\lambda V_{k k} \delta_{i j}+2 \mu V_{i j} .
$$

Combining equations

$$
\sigma_{k k}=-3 p+(3 \lambda+2 \mu) V_{k k} .
$$

If the mean normal stress $1 / 3 \sigma_{k k}$ is assumed to be independent of the volume expansion rate $V_{k k}$, then there must be

$$
3 \lambda+2 \mu=0 .
$$

Thus, the constitutive equation becomes

$$
\sigma_{i j}=-p \delta_{i j}+2 \mu V_{i j}-\frac{2}{3} \mu V_{k k} \delta_{i j} .
$$

This formula was put forward by Stokes, so the fluid subject to the above equation is called Stokes fluid, for this kind of fluid only a material constant $\mu$ (i.e., viscosity coefficient) is enough to determine its properties.

If the fluid is incompressible, then $V_{k k}=0$, and the constitutive equation of incompressible viscous fluid can be obtained:

$$
\sigma_{i j}=-p \delta_{i j}+2 \mu V_{i j}
$$

If $\mu=0$, the constitutive equation of inviscid fluid is obtained:

$$
\sigma_{i j}=-p \delta_{i j}
$$

The appearance of hydrostatic pressure $P$ marks the fundamental difference between hydrodynamics and elasticity. To accommodate the needs of this new variable, it is usually assumed that there exists some equation of state, which gives the relationship between density $\rho$, pressure $P$, and absolute temperature $T$, that is

$$
f(p, \rho, T)=0 .
$$

3.3. Finite Element Model. The bird strike setup is conducted based on the experiment of the bird-impact plate in Figure 3 by using LS-DYNA element code.

The flat plate fixed along the four edges is impacted by a soft body at the center of the flat plate at $91.1 \mathrm{~m} / \mathrm{s}$ with an impact angle of $30^{\circ}$. The dimensions of the flat plate are $525 \mathrm{~mm} \times 430 \mathrm{~mm} \times 10 \mathrm{~mm}$. The geometric model of a bird is simulated by a cylinder with a hemisphere at the two ends, the diameter of the hemisphere is $53 \mathrm{~mm}$ and the length of the cylinder is $156 \mathrm{~mm}$. The mass of the bird is $1.8 \mathrm{~kg}$.

In the finite element model, the 8-node solid and 164element type in the LS-DYNA element library is employed for the bird and flat plate. In addition, hourglass control and single-point integration are also used. The numbers of the elements for the bird and flat plate model are 4504 and 2000.

\subsection{Materials Properties}

3.4.1. Materials Properties of Flat Plate. The plate is made from LY12-CZ aluminum alloy. The material parameters of the flat plate are mentioned in Table 1. The material 


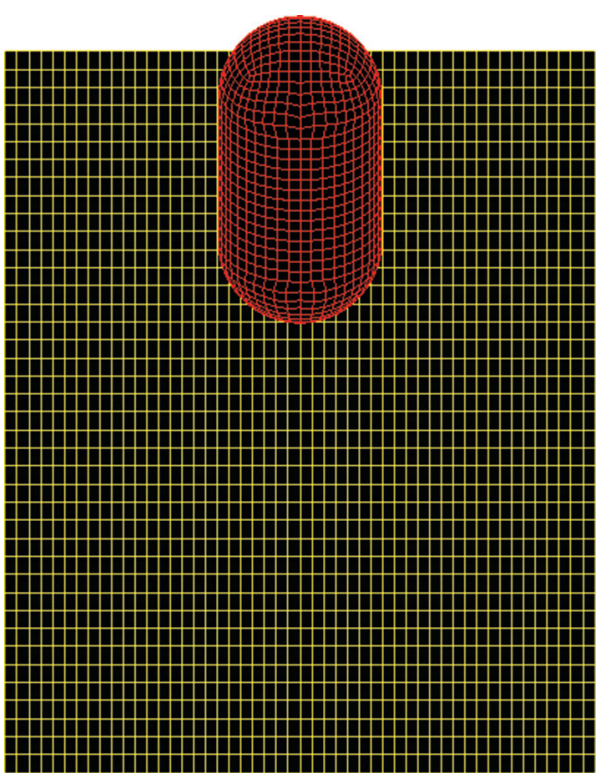

(a)

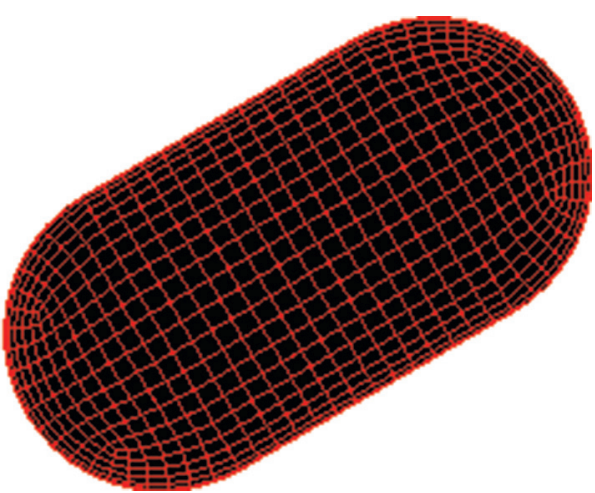

(b)

Figure 3: The finite element model: (a) top view; (b) front view.

TABLE 1: Material parameters of flat plate.

\begin{tabular}{lcccc}
\hline Young's modulus $(\mathrm{GPa})$ & Poisson ratio & Density $\left(\mathrm{kg} / \mathrm{m}^{3}\right)$ & Yield stress $(\mathrm{MPa})$ & Failure strain \\
\hline 71 & 0.3 & 2780 & 690 & 0.3 \\
\hline
\end{tabular}

properties of the flat plate are modeled by the MAT_PLASTIC_KINEMATIC in LS-DYNA code where the values are set in Table 1.

3.4.2. Material Properties of Bird. Generally speaking, a trend is visible towards the utilization of SPH models with an equation of state for the material of bird using the properties of water-air-mixture at room temperature. A very good correlation to experimental results could be obtained with these models. For the fluid model, in LS-DYNA, the material model of NULL (empty material) is used to describe its material properties. The parameters to be input are shown in Table 2.

According to the property of the bird in the experiment, using fluid constitutive and Gruneisen state equation to describe soft body is closer to the reality. The bird model is defined by MAT_NULL and the equation of state (EoS) is specified. The inputs of parameters are shown in Table 3.

During the impact process, the deformation of the bird is described by the equation of state. Elastic modulus and passion ratio are 0 , and the density is $938 \mathrm{~kg} / \mathrm{m}^{3}$. The four parameters of the constitutive model of the bird to be determined are shown in Table 4.

3.5. Identification of the Bird Model and the Inversion of the Parameters. The displacements at 12 different times are chosen as the inputs, and the outputs of the model are four constitutive parameters of the soft body. The 12 different times are based on the experimental displacement-time data
TABLE 2: Parameters of NULL model.

\begin{tabular}{lc}
\hline RO & Mass density \\
PC & Pressure cutoff \\
MU & Viscosity coefficient \\
TEROD & Relative vol. in tension \\
CEROD & Relative vol. in compression \\
YM & Young's modulus \\
PR & Poisson's ratio \\
\hline
\end{tabular}

TABle 3: Parameters of Gruneisen model.

\begin{tabular}{lccccccc}
\hline C & S1 & S2 & S3 & GAMA0 & A & E0 (J) & V0 \\
\hline 1670 & 2.48 & 0 & 0 & 0 & 0 & 0 & 1 \\
\hline
\end{tabular}

TABle 4: Parameters to be determined.

\begin{tabular}{lc}
\hline PC & Pressure cutoff \\
MU & Viscosity coefficient \\
TEROD & Relative vol. in tension \\
CEROD & Relative vol. in compression \\
\hline
\end{tabular}

of the center of the flat plate. The experimental displacement-time data of the center of the flat plate is given in Figure 4 .

Before the network training, both input and output variables are normalized within the range 0 to 1 in order to obtain a reliable form for the neural network ${ }^{[31]}$. If the number of hidden layers is too small, the trained network might not have sufficient ability to learn the process correctly. As a result, in order to choose the appropriate number 


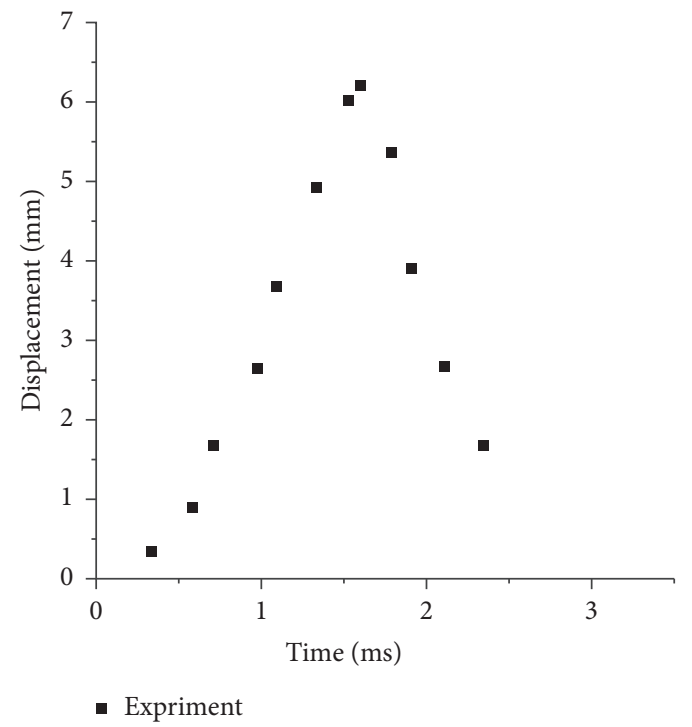

Figure 4: Experimental displacement-time data of the center of the flat plate.

of hidden layers, the trial-and-error procedure is started with seven neurons in the hidden layer and further carried out with up to fourteen neurons. It is found that when the number of neurons is 9 , the mean square error reaches the minimum.

In the bird constitutive model, the values of the four parameters have their ranges based on the prior knowledge, specific ranges (see Table 5).

The parameters to be optimized are uniformly divided into a number of values with the space. According to the orthogonal design and uniform design principle, these values are divided into 25 groups, and each sample group contains four parameters, which is shown in Table 6.

Substituting these parameters of 25 groups into the bird constitutive model, 25 displacement-time curves of the center of the flat plate can be obtained in LS-DYNA simulation. Selecting the displacements of the center of the flat plate, the training of the network can be finished, which is shown in Table 7.

When developing the ANN model, the samples of 1,5 , $10,15,20$, and 25 are removed to test the generalization capability of the network. The optimized ANN model consists of 12 input neurons, 4 output neurons, and a single hidden layer (with 9 neurons) and the transfer functions of the optimized ANN model are 'tan sigmoid' and 'pure linear'. A feedforward backpropagation algorithm is selected to train the network. The setting of other training parameters for the neural network is listed in Table 8 .

\section{Results and Discussion}

The performance of ANN in the training stage is shown in Figure 5. It can be seen that the trend of error reduction remains unchanged after 2000 training cycles. After being trained, the ANN model can map the nonlinear relationship between the parameters of the bird constitutive model and the displacements of the center of the flat plate.
TABLE 5: The value range of the four parameters.

\begin{tabular}{lccc}
\hline Optimize parameters & Label & Ranges of values & Units \\
\hline PC & $X_{1}$ & {$[-0.05,-1.25]$} & $\mathrm{MPa}$ \\
MU & $X_{2}$ & {$[0,1.5]$} & $\mathrm{N} \cdot \mathrm{ms} / \mathrm{mm}^{2}$ \\
TEROD & $X_{3}$ & {$[0.05,1.25]$} & - \\
CEROD & $X_{4}$ & {$[0.05,1.25]$} & - \\
\hline
\end{tabular}

TABle 6: Parameters in sample groups.

\begin{tabular}{lcccc}
\hline Sample groups & $X_{1}$ & $X_{2}$ & $X_{3}$ & $X_{4}$ \\
\hline 1 & -0.05 & 0 & 0.05 & 1.25 \\
2 & -0.1 & 0.1 & 0.1 & 1.2 \\
3 & -0.15 & 0.2 & 0.15 & 1.15 \\
4 & -0.2 & 0.3 & 0.2 & 1.1 \\
5 & -0.25 & 0.4 & 0.25 & 1.05 \\
$\ldots \ldots \ldots$ & $\ldots \ldots \ldots$ & $\ldots \ldots \ldots$ & $\ldots \ldots \ldots$ & $\ldots \ldots \ldots$ \\
\hline
\end{tabular}

The optimized parameters can be obtained, as can be seen in Table 9. The comparison of the numerical and experimental displacement of the center of the flat plate using the optimized constitutive model of bird is shown in Figure 6, indicating the simulation result using the parameters obtained from the developed network is in good agreement with experimental data. In order to verify the identification of the constitutive model after optimization, a comparative evaluation of three other constitutive equations and the present bird constitutive model is carried out. The parameters and stress distributing graphs of elastic model, plastic kinematic model, and elasticplastic hydrodynamic Model are shown in Tables 10-12 and Figure 7, respectively, and the parameters of EOS_LINEAR_POLYNOMIA are shown in Table 13. As can be seen in Figure 8, the model of the bird remains in good condition while the flat plate with obvious deformation in the elastic model. The result of the plastic kinematic model and the elastic-plastic hydrodynamic model show a similar 
TABLE 7: Sample groups.

\begin{tabular}{|c|c|c|c|c|c|c|}
\hline \multirow{2}{*}{ Time/ms } & \multicolumn{6}{|c|}{ Sample groups (Displacement/mm) } \\
\hline & 1 & 2 & 3 & 4 & 5 & \\
\hline 0.34 & 0.123064 & 0.123165 & 0.123333 & 0.122845 & 0.121246 & $2 \ldots \ldots$ \\
\hline 0.59 & 1.220337 & 1.216867 & 1.216224 & 1.213989 & 1.232132 & $\ldots \ldots \ldots$ \\
\hline 0.71 & 2.043114 & 2.048179 & 2.048194 & 2.048631 & 2.060089 & $\ldots \ldots \ldots$ \\
\hline 0.98 & 4.100285 & 4.112417 & 4.128776 & 4.153035 & 4.19781 & $\ldots \ldots \ldots$ \\
\hline 1.09 & 4.668175 & 4.686835 & 4.689432 & 4.709893 & 4.751519 & $\ldots \ldots$ \\
\hline 1.34 & 5.355844 & 5.376423 & 5.394958 & 5.417252 & 5.453059 & $\ldots$ \\
\hline 1.53 & 5.576561 & 5.608154 & 5.628895 & 5.652006 & 5.696968 & $\ldots \ldots \ldots$ \\
\hline 1.60 & 5.537479 & 5.571992 & 5.605718 & 5.646124 & 5.67513 & $\ldots \ldots \ldots$ \\
\hline 1.79 & 4.84706 & 4.895124 & 4.93118 & 4.952708 & 4.973954 & $\ldots \ldots \ldots$ \\
\hline 1.91 & 4.184824 & 4.227517 & 4.255795 & 4.27969 & 4.277913 & $\ldots \ldots \ldots$ \\
\hline 2.11 & 3.242367 & 3.260473 & 3.273862 & 3.262928 & 3.225929 & $\ldots \ldots \ldots$ \\
\hline 2.35 & 2.13491 & 2.12319 & 2.114001 & 2.076703 & 2.046814 & $\ldots \ldots \ldots$ \\
\hline
\end{tabular}

TABLE 8: The setting of training parameters for network.

\begin{tabular}{lc}
\hline Name of parameters & Contents \\
\hline Network & Backpropagation \\
Training function & Trainlm \\
Performance function & MSE \\
Training epoch & 2,000 \\
Goal & 0.001 \\
\hline
\end{tabular}

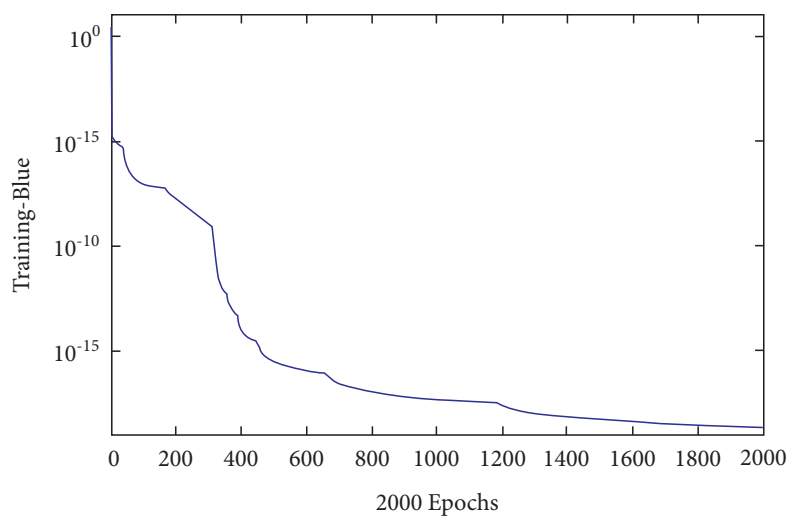

FIGURE 5: Training convergence curve of the neural network model.

TABLE 9: The results of parametric inversion.

\begin{tabular}{lccc}
\hline Optimized parameters & Label & Range of values & Optimized results \\
\hline PC & $X_{1}$ & {$[-0.05,-1.5]$} & -0.3705 \\
MU & $X_{2}$ & {$[0,1.5]$} & 0.641 \\
TEROD & $X_{3}$ & {$[0.05,1.25]$} & 0.34 \\
CEROD & $X_{4}$ & {$[0.05,1.25]$} & 0.9295 \\
\hline
\end{tabular}

phenomenon that the model of bird has large deformation while the flat plate with little, and the fringe levels drop significantly.

During the impact process, different bird constitutive models result in different displacement and force-time histories of the center of the flat plate. The maximum displacement and the force of the center of the flat plate of the elastic constitutive model are the largest among the four constitutive models, in which the deviations from experimental results are also the largest. Figure 9 shows that the present bird constitutive model developed from the present network is in better agreement with experimental data than the other three constitutive models. 


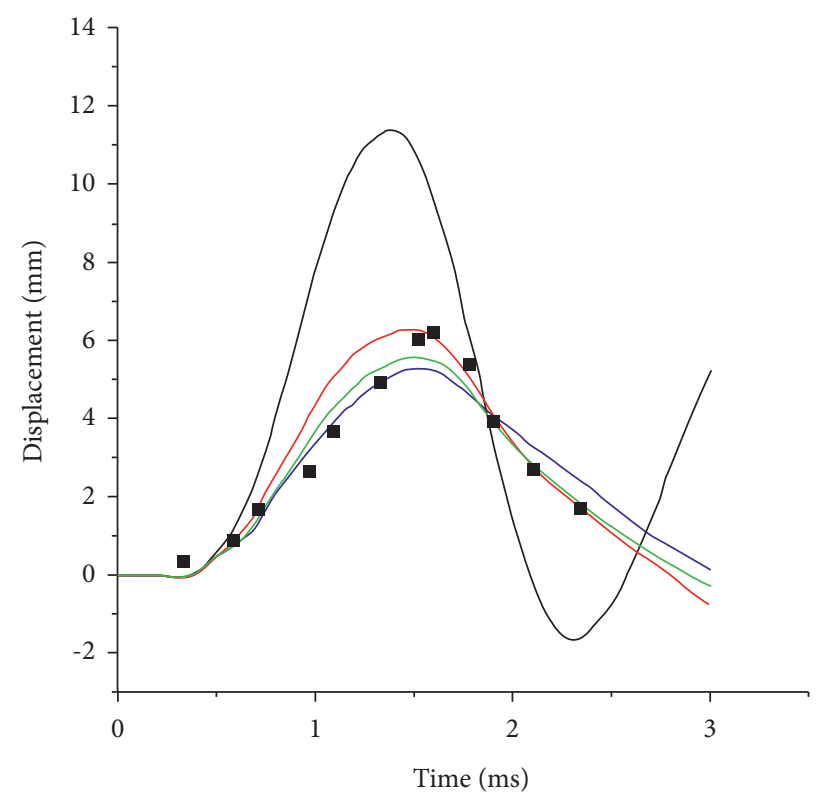

- Expriment _ Fluid

— Optimized _ Plastic

_- Elastic

FIGURE 6: Comparisons of the numerical displacements among different constitutive models.

Table 10: Parameters of elastic model.

\begin{tabular}{lcc}
\hline Elastic modulus $/ \mathrm{Pa}$ & Poisson ratio & Density $/ \mathrm{kg} / \mathrm{m}^{3}$ \\
\hline $6.89 \times 10^{7}$ & 0.49 & 938
\end{tabular}

TABLE 11: Parameters of plastic kinematic model.

\begin{tabular}{lcccc}
\hline Elastic modulus $/ \mathrm{Pa}$ & Poisson ratio & Density $/ \mathrm{kg} / \mathrm{m}^{3}$ & Yield stress $/ \mathrm{Pa}$ & Failure strain \\
\hline $6.89 \times 10^{7}$ & 0.49 & 938 & 6894 & 1.25 \\
\hline
\end{tabular}

TABLe 12: Parameters of elastic-plastic hydrodynamic model.

\begin{tabular}{lccccc}
\hline Density $/ \mathrm{kg} / \mathrm{m}^{3}$ & Shear modulus $/ \mathrm{MPa}$ & Hardening modulus $/ \mathrm{MPa}$ & Pressure cutoff/MPa & Yield stress/MPa & Failure strain \\
\hline 938 & 10.2 & 0.13 & -0.9 & 0.03 & 0.95 \\
\hline
\end{tabular}




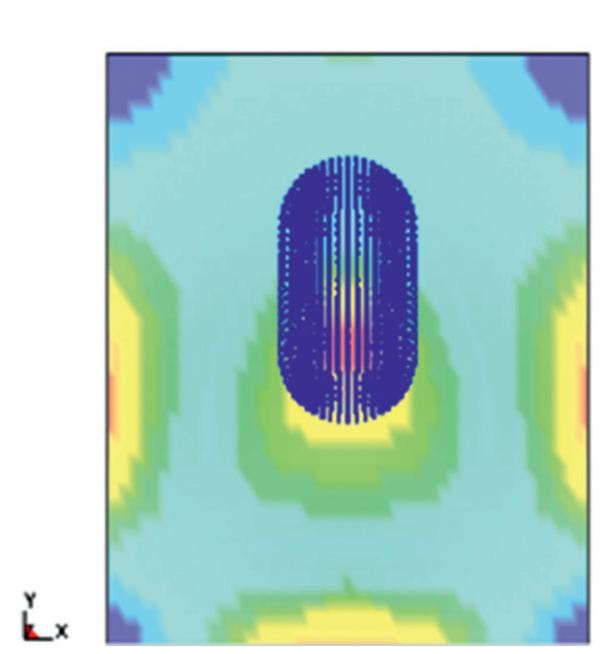

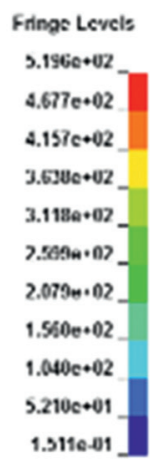

Finge Levels

$3.1960+02$

$4.677 \mathrm{e} \cdot 02$

$4.157 \mathrm{c} \bullet 02$

$3.6300+02$

$3.118 \mathrm{e} \cdot 02$

2.509a $\cdot 0 ?$

$2.079 w \cdot 02$

$1.540 e \cdot 02$

$1.040 \mathrm{e} \cdot 02$

5.2100001

1.3110-01

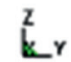

(a)

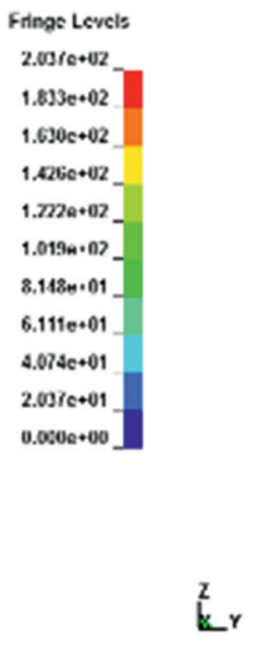

Fringe Levels

$2.0010+02$

$1.833 \mathrm{e}+02$

$1.630 \mathrm{c}+02$

$1.4260 \cdot 02$

$1 . m \mathrm{a}+02$

1.019m ค n? -

$8.148 m \cdot 01$

$6.111 e \cdot 01$

$4.074 e+01$

$2.0970+01$

$0.020 \mathrm{e}+00$

(b)

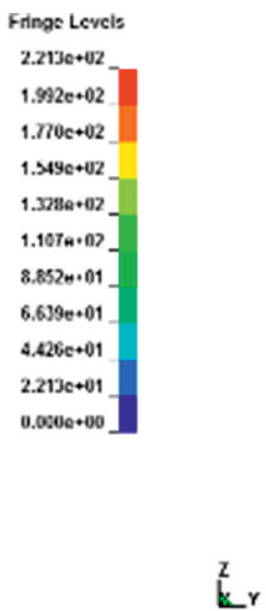

Fringe Levels

$2.2130+02$

$1.992 \mathrm{e} \cdot 02$

$1.770 \mathrm{c} \cdot 02$

$1.549 \mathrm{c} \cdot 02$

$1.3780 \cdot 02$

$1.107 \mathrm{~A} \cdot \mathrm{n?}$

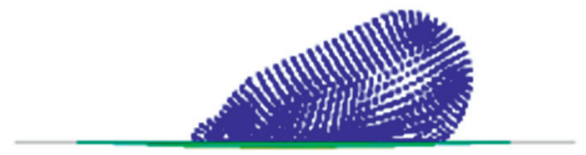

$8.852 w \cdot 01$

$6.6390 \cdot 01$

$4.426 \mathrm{e} \cdot 01$

$2.213 c+01$

$0.0000+00$

(c)

FIgURE 7: Stress distributing graphs of the top view and front view at $1.5 \mathrm{~ms}$ time of impact: (a) elastic model; (b) plastic kinematic model; (c) elastic-plastic hydrodynamic model.

TABLe 13: Eos linear polynomial.

\begin{tabular}{ccccccccc}
\hline$C_{0}$ & $C_{1}$ & $C_{2}$ & $C_{3}$ & $C_{4}$ & $C_{5}$ & $C_{6}$ & $E_{0}$ & $V_{0}$ \\
\hline 0 & 2072 & 6217 & 10362 & 0 & 0 & 0 & 0
\end{tabular}

Unit: $\left(C_{0} \sim C_{6}, \mathrm{~N} / \mathrm{mm}^{2} ; E_{0}\right.$, J; $V_{0}$, no unit). 


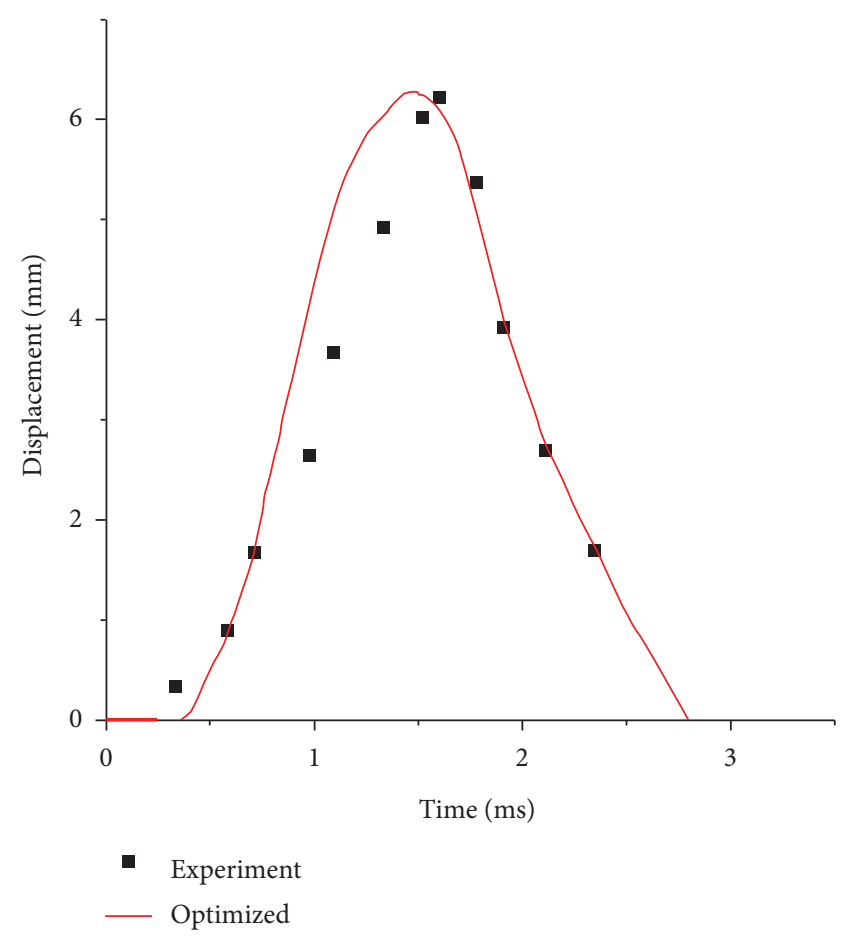

FIgURE 8: The comparison of numerical and experimental displacement of the center of the flat plate.

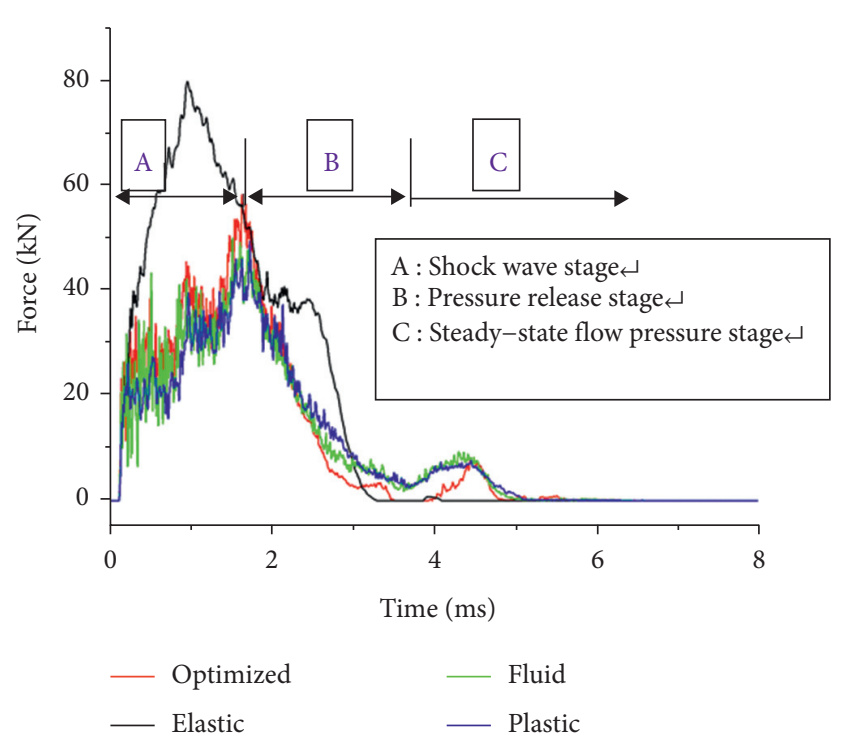

Figure 9: Comparisons of the force-time curves among different models.

\section{Conclusion}

In this paper, the artificial neural network model with a backpropagation learning algorithm was used to develop the constitutive relationship for the soft body during the impact process. The feasibility and practicability of this identification method were verified through a specific example. From the results of this present study, the main conclusions are drawn as follows:
(1) Different flexible body constitutive models are used, and the impact of the soft body presents different modes, and the displacement curve and impact force curve of the aluminum plate center is also different. Among them, the displacement and impact force of the linear elastic constitutive model is the largest, but the deviation from experimental results is also the largest.

(2) The calculated results of the soft body constitutive parameters optimized by the improved BP neural network algorithm are in good agreement with the experimental results. At the same time, it can be seen that the calculation curve optimized by BP neural network algorithm almost passes all the test points, which proves the accuracy and reliability of the optimized flexible body parameters, and the calculation convergence accuracy also meets the requirements.

(3) As a calculation method, BP neural network can be used in the optimization calculation of constitutive parameters of soft body impact. However, it should be pointed out that each constitutive model needs to build its own neural network when it is used for calculation, and the optimization results and errors will be different due to the difference of network structure.

\section{Data Availability}

The data used to support the findings of this study are included within the paper.

\section{Conflicts of Interest}

The authors declare that there are no conflicts of interest regarding the publication of this paper.

\section{Acknowledgments}

This study was funded by National Natural Science Foundation (12102095), the Scientific Research Project for Young Innovative Talents of Guangxi Province (20200312), Research grant for Talent of Guangxi Plan (100), the starting research grant for High-level Talents from Guangxi University, the Science and Technology Major Project of Guangxi Province (AA18118055), the Guangxi Natural Science Foundation (20181096), and application of key technology in building construction of prefabricated steel structure (20190528).

\section{References}

[1] J. Thorpe, "Update on fatalities and destroyed civil aircraft due to bird strikes with appendix for 2008 \& 2009," in Proceedings of the 29th International Bird Strike Committee Meeting, Cairns, Australia, 2010.

[2] D. Zhang and Q. Fei, "Effect of bird geometry and impact orientation in bird striking on a rotary jet-engine fan analysis using SPH method," Aerospace Science and Technology, vol. 54, no. 54, pp. 320-329, 2016. 
[3] S. Zhu, M. Tong, and Y. Wang, "Experiment and numerical simulation of a full-scale aircraft windshield subjected to bird impact," in Proceedings of the 50th AIAA/ASME/ASCE/AHS/ ASC Structures, Structural Dynamics, and Materials Conference, Palm Springs, CA, USA, May 2009.

[4] R. Doubrava and V. Strnad, "Bird strike analyses on the parts of aircraft structure," in Proceedings of the 27th Congress of the International Council of the Aeronautical Sciences, Nice, France, September 2010.

[5] Y. K. Zhang and Y. L. Li, "Analysis of the anti-bird impact performance of typical beam-edge structure based on ANSYS/ LS-DYNA," Advanced Materials Research, vol. 33-37, pp. 395-400, 2008.

[6] J. L. Yang, X. J. Cai, and C. H. Wu, "Experimental and FEM study of windshield subjected to high speed bird impact," Acta Mechanica Sinica, vol. 19, no. 6, pp. 543-550, 2003.

[7] F. Stoll and R. A. Brockman, "Finite elelment simulation of fflgh-speed soft-body impacts," 1997.

[8] Y. N. Gong and S. Q. Xu, "Bird impact analysis of aircraft windshield transparency," Chinese Journal of Aeronautics, vol. 5, no. 2, 1992.

[9] Y. Zhou, Y. Sun, and W. Cai, "Bird-striking damage of rotating laminates using SPH-CDM method," Aerospace Science and Technology, vol. 84, no. 84, pp. 265-272, 2019.

[10] S. A. Meguid, R. H. Mao, and T. Y. Ng, "FE analysis of geometry effects of an artificial bird striking an aeroengine fan blade," International Journal of Impact Engineering, vol. 35, no. 6, pp. 487-498, 2008.

[11] A. Khan, R. Kapania, and E. Johnson, "A review of soft body impact on composite structure," in Proceedings of the 51st AIAA/ ASME/ASCE/AHS/ASC Structures, Structural Dynamics, and Materials Conference 18th AIAA/ASME/AHS Adaptive Structures Conference, Orlando, FL, USA, April 2010.

[12] R. H. Mao, S. A. Meguid, and T. Y. Ng, "Effects of incidence angle in bird strike on integrity of aero-engine fan blade," International Journal of Crashworthiness, vol. 14, no. 4, pp. 295-308, 2009.

[13] S. Q. Jia, F. S. Wang, J. J. Zhou, Z. Jiang, and B. Xu, "Study on the mechanical performances of carbon fiber/epoxy composite material subjected to dynamical compression and high temperature loads," Composite Structures, vol. 258, Article ID 113421, 2021.

[14] M. Anghileri, L. L. Castelletti, and D. Molinelli, "A strategy to design bird-proof spinners," in Proceedings of the 7th European LS-DYNA Users Conference, Salzburg, Austria, May 2009.

[15] M. Anghileri, L. Castelletti, and V. Mazza, "Birdstrike: approaches to the analysis of impacts with penetration," Impact loading of lightweight structures, vol. 49, pp. 63-74, 2005.

[16] L. S. Nizampatnam, "Models and methods for bird strike load predictions," 2007.

[17] M. A. Mccarthy, J. R. Xiao, C. T. Mccarthy et al., "Modelling of bird strike on an aircraft wing leading edge made from fibre metal laminates-part 2: modelling of impact with SPH bird model," Applied Composite Materials, vol. 11, no. 5, pp. 317-340, 2004.

[18] M. A. Lavoie, A. Gakwaya, M. N. Ensan, D. G. Zimcik, and D. Nandlall, "Bird's substitute tests results and evaluation of available numerical methods," International Journal of Impact Engineering, vol. 36, pp. 1276-1287, 2009.

[19] M. Nishikawa, K. Hemmi, and N. Takeda, "Finite-element simulation for modeling composite plates subjected to softbody, high-velocity impact for application to bird-strike problem of composite fan blades," Composite Structures, vol. 93, no. 5, pp. 1416-1423, 2011.
[20] L. Y. Darryl, L. C. John, M. E. Richard, and L. W. Kate, "Hazing and movements of Canada geese near Elmendorf air force base in Anchorage, Alaska," International Biodeterioration \& Biodegradation, vol. 45, pp. 103-110, 2000.

[21] A. F. Johnson and M. Holzap, "Modelling soft body impact on composite structures," Composite Structures, vol. 61, no. 1-2, pp. 103-113, 2003.

[22] M. A. Lavoie, A. Gakwaya, and M. N. Ensan, "Validation of available approaches for numerical bird strike modeling tools," International Review of Mechanical Engineering, vol. 1, 2013.

[23] F. Allaeys, G. Luyckx, and W. V. Paepegem, "Characterization of real and substitute birds through experimental and numerical analysis of momentum, average impact force and residual energy in bird strike on three rigid targets: a flat plate, a wedge and a splitter," International Journal of Impact Engineering, vol. 99, pp. 1-13, 2017.

[24] R. Hedayati, M. Sadighi, and M. Mohammadi-Aghdam, "On the difference of pressure readings from the numerical, experimental and theoretical results in different bird strike studies," Aerospace Science and Technology, vol. 32, pp. 260-266, 2014.

[25] R. Hedayati and S. Ziaei-Rad, "A new bird model and the effect of bird geometry in impacts from various orientations," Aerospace Science and Technology, vol. 28, pp. 9-20, 2013.

[26] J. Liu and Y. L. Li, "Numerical simulation of a rotary engine primary compressor impacted by bird," Chinese Journal of Aeronautics, vol. 4, no. 26, pp. 926-934, 2013.

[27] J. M. Zurada, Introduction to Artificial Neural Systems, Jaico Publishing House, Chennai, India, 1992.

[28] Y. Zhang and Y. Li, "Identification of the bird constitutive model," in Proceedings of the 3rd International Conference on Mechanical Engineering and Mechanics, Beijing China, June 2009.

[29] K. Swingler, Applying Neural Networks: A Practical Guide, Morgan Kaufmann, SanFrancisco, CA, USA, 1996. 